\title{
Autonomie und Normativität
}

\author{
$\mathrm{Zu}$ Hegels Rechtsphilosophie \\ Hrsg. v. Kurt Seelmann u. Benno Zabel
}

Autonomie und

Normativität

Herausgegeben von

KURT SEELMANN Un BENNO ZABEL

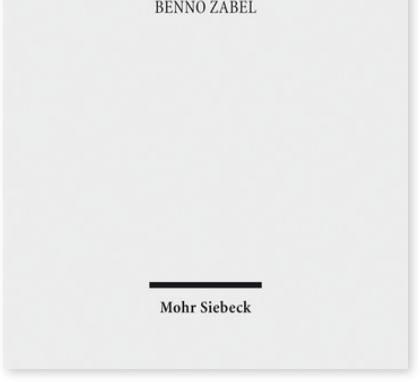

2014. XII, 449 Seiten.

ISBN 978-3-16-153093-7

DOI 10.1628/978-3-16-153093-7

eBook PDF 94,00€

ISBN 978-3-16-152812-5

fadengeheftete Broschur 94,00
Autonomie und Normativität sind Schlüsselbegriffe der Gegenwart. Gleichwohl ist deren Bedeutung für die Legitimation moderner Gemeinwesen immer kontrovers geblieben. Für die Begründung wird entweder auf das individualistische Modell der Aufklärungsphilosophie seit Locke und Kant oder auf den Vorrang der Gemeinschaft im Sinne einer politischen Romantik abgestellt. Hegel hält beide Positionen für defizitär. Er insistiert zwar darauf, dass Personalität Resultat eines

Vergemeinschaftungsprozesses ist und steht deshalb in normativer Hinsicht dem Individualismus nahe, ohne aber den Weg eines »romantischen Kommunitarismus« zu gehen. Der vorliegende Band will diese Sichtweise Hegels nicht nur herkömmlichen Hegeldeutungen gegenüber stellen, sondern auch mit heute dominierenden rechtsphilosophischen Positionen konfrontieren.

\section{Inhaltsübersicht}

\section{Autonomie, Normativität, Person}

Jean-Francois Kervegan : Person, Subjekt, Institution. Bemerkungen über die Tiefstrukturen der Rechtsphilosophie Hegels Giacomo Rinaldi : Hegel und das philosophische Verständnis der Person - Heikki lkäheimo : Fichte on Recognizing Potential Persons - Carla De Pascale : Kommentar zu Heikki Ikäheimo: »Fichte on Recognizing Potential Persons« - Stephan Stübinger : Hegel und das moderne Verständnis der Person im Recht

\section{Autonomie, Normativität, Anerkennung}

Sabrina Zucca-Soest : Das Recht der Menschenwürde - Christoph Enders : Das Recht der Menschenwürde. Kommentar: Die Institutionalisierung der Rechts-Subjektivität des Menschen in Hegels Rechts- und Staatsphilosophie - Gerhard Luf : Institutionelle Dimensionen der Menschenwürde bei Hegel

\section{Autonomie, Normativität, Recht}

Benno Zabel: Das Recht der Institutionen. Zu einer Kultur der Freiheit jenseits von Individualismus und Kollektivismus Sebastian Rödl : Recht als Dasein des freien Willens - Klaus Vieweg : Die bürgerliche Gesellschaft als 'Verstandesgemeinschaft' - Zur logischen Grundlegung von Hegels praktischer Philosophie - Wolfgang Schild : Geschworenengericht und Strafrechtsinstitution - Diethelm Klesczewksi : Kommentar zu Wolfgang Schild: "Geschworenengericht und Strafrechtsinstitution« - Katrin Gierhake : Kommentar zu Wolfgang Schild:

»Geschworenengericht und Strafrechtsinstitution« - Stephan Kirste : Hegel und der postnationale Verfassungsstaat. Supranationale bürgerliche Gesellschaft und sittliche öffentliche Ordnung am Beispiel der Europäischen Union

\section{Autonomie, Normativität,Geschichte}

Christian Schmidt : Das Recht der Geschichte - Günter Dux : Radikale Historisierung. Zur unzeitgemäßen Genialität der Philosophie der Geschichte Hegels - Pirmin Stekeler-Weithofer : Logik der Geschichte und Geschichte im Begriff. Zum notwendigen Holismus in jeder Praxisformanalyse

\section{Autonomie, Normativität, Natur}

Kenneth Westphal : Autonomie und Freiheit verkörperter Personen. Bemerkungen zu Hegel und den heutigen Lebenswissenschaften - Daniela Demko : Autonomie in den Life Sciences und Hegels Institutionenlehre - Ludwig Siep : Freiheit, soziale Identität und Natur in Hegels praktischer Philosophie

VI. Autonomie, Normativität, Ethik

Klaus-Michael Kodalle : Spannungen und Gewichtsverlagerungen im Verzeihungsdiskurs des Deutschen Idealismus - Kurt Seelmann : Ethische Räume jenseits rechtlicher Institutionen? Gnade, Versöhnung und Verzeihung bei Hegel - Elisabeth Weisser-Lohmann : Ethische Räume jenseits rechtlicher Institutionen? Ein Kommentar zu den Beiträgen von Kurt Seelmann und Klaus-Michael Kodalle - Erzsébet Rózsa: Versöhnung jenseits und diesseits rechtlicher Institutionen bei Hegel

\section{Autonomie, Normativität, Metaphysik}

Walter Jaeschke : Das Ewige, das gegenwärtig ist - Metaphysik und Naturrecht - Birgit Sandkaulen : Probleme mit dem »unbefangenen Bewußtsein«. Kommentar zu Walter Jaeschke - Christian Georg Martin : Die Idee als Einheit von Begriff und Objektivität

Kurt Seelmann ist emeritierter Ordinarius für Strafrecht und Rechtsphilosophie an der Universität Basel.

Benno Zabel Geboren 1969; Studium der Rechtswissenschaft, Philosophie und Germanistik; 2007 Promotion; 2014 Habilitation; seit 2015 Professor für Strafrecht und Rechtsphilosophie an der Rheinischen Friedrich-Wilhelms-Universität Bonn. 
Jetzt bestellen:

https://mohrsiebeck.com/buch/autonomie-und-normativitaet-9783161530937?no_cache=1 order@mohrsiebeck.com

Telefon: +49 (0)7071-923-17

Telefax: +49 (0)7071-51104

Mohr Siebeck GmbH \& Co. KG

Postfach 2040

D-72010 Tübingen

info@mohrsiebeck.com

Mohr Siebeck

www.mohrsiebeck.com 